\title{
Neuroimaging in Stroke Recovery: A Position Paper from the First International Workshop on Neuroimaging and Stroke Recovery
}

\author{
Workshop Participants: (Writing Committee \\ Indicated by Asterisks) \\ Baron, Jean-Claude* \\ Black, Sandra E. \\ Butler, Andrew J. \\ Carey, James \\ Chollet, Francois \\ Cohen, Leonardo G.* \\ Corbetta, Maurizio \\ Cramer, Steven C.* \\ Dobkin, Bruce H. ${ }^{*}$ \\ Frackowiak, Richard \\ Heiss, W.D. \\ Johansen-Berg, Heidi* \\ Krakauer, John W. \\ Lazar, Ronald M. \\ Lennihan, Laura L. \\ Marshall, Randolph S.* \\ Matthews, Paul \\ Mohr, J.P. \\ Nelles, Gereon \\ Pascual-Leone, Alvaro \\ Pomeroy, Valerie \\ Rijntjes, Michel \\ Rossini, Paolo Maria \\ Rothwell, John C. \\ Seitz, Rüdiger J. \\ Small, Steven L. \\ Sunderland, Alan \\ Ward, N.S.* \\ Weiller, Cornelius \\ Wise, Richard J.S.
}

Loubinoux, Isabelle*

apply functional neuroimaging to the development of rational treatment strategies for enhanced stroke recovery.

Presented herein is a summary statement of topics discussed at the workshop. These included (i) the clinical relevance of functional imaging changes after stroke for the motor and language systems; (ii) the technical challenges faced in moving towards establishing functional neuroimaging as a clinically useful tool; (iii) the contributions of neurophysiological probes such as transcranial magnetic stimulation (TMS) to improve understanding of the mechanisms underlying brain reorganization after stroke; and (iv) the potential role of neuroimaging in the assessment and development of rational pharmacological and behavioral therapies.

\section{Clinical Relevance}

Functional recovery commonly occurs in surviving stroke patients in the weeks and months following the injury. There is evidence from animal models that cerebral reorganization underlies at least some of this recovery and it is hoped that an understanding of the neurophysiological processes underlying this reorganization in the human brain will lead to a rational approach to the treatment of impairment. In animal models, focal brain damage triggers a number of changes at the molecular, cellular, and systems level, some of which alter the potential for cerebral reorganization and consequent functional recovery. Although the same techniques are not available to study the working human brain, functional brain imaging has provided insights into how the human brain responds to focal injury.

This conference was made possible by the Charles and Jean Brunie Foundation and The Richard and Jenny Levine Foundation.

\begin{tabular}{ll}
\hline KARGER & (c) 2004 S. Karger AG, Basel \\
1015-9770/04/0183-0260\$21.00/0 \\
$\begin{array}{l}\text { Fax +4161306 1234 } \\
\text { E-Mail karger@karger.ch } \\
\text { www.karger.com }\end{array}$ & $\begin{array}{l}\text { Accessible online at: } \\
\text { www.karger.com/ced }\end{array}$
\end{tabular}

Prof. Randolph S. Marshall

Columbia University Medical Center

710 W. 168th Street

New York, NY 10032 (USA)

Tel. +1 212305 8389, Fax +1 212305 3741, E-Mail rsm2@columbia.edu 
Most functional imaging studies in stroke survivors have focused on the motor or language system. Several exhaustive reviews of these studies can be found elsewhere [1-5]. The following section will concentrate on the clinical relevance of these studies, and whether there are common themes to be derived from seemingly conflicting data.

\section{Motor Recovery Studies}

Positron emission tomography (PET) and functional magnetic resonance imaging (fMRI) consistently demonstrate relative overactivations in motor-related brain regions during movement of the stroke-affected upper extremity compared to control subjects. In particular, additional task-related recruitment in the unaffected hemisphere has often been reported, rendering the activation pattern more bilateral. These increases are largely restricted to known motor-related regions, in particular the primary sensorimotor cortex, dorsolateral premotor cortex $(\mathrm{PMd})$, ventrolateral premotor cortex $(\mathrm{PMv})$, supplementary motor area (SMA), cingulate motor areas (CMA), parietal cortex, insula cortex and cerebellum [see, e.g., 6-11]. There are also differences in brain activation patterns between individual stroke patients. Among chronic stroke patients, those with no residual impairment tend to have relatively normal activation maps compared to controls, while patients with more marked impairment exhibit greater recruitment in ipsilesional primary motor cortex (M1) [see, e.g., 12, 13] as well as in secondary motor areas bilaterally [13]. Other studies have demonstrated that a more bilateral pattern of activation in M1 as assessed by a laterality index is seen in those patients with poorer outcome $[12,14]$.

Other consistent findings relate to the topography of ipsilesional M1 activation, with extension of activation cluster towards the face area and posterior displacement of peak activation being consistently reported $[8,11,15$, 16]. However, the clinical significance of these findings remains elusive.

A key issue is how recovery or outcome is defined. In several studies patients were considered well recovered if they had made substantial functional gains to the point of being able to perform the motor task, e.g. finger tapping. Average group activation maps for stroke patients in these studies demonstrate increases in activation compared to controls, but it is likely that some patients in these groups had at least mild impairment. For instance, in a study where outcome was assessed using several different measures, a negative linear correlation between motor outcome and task-related brain activation was seen in a num- ber of primary and secondary motor areas [13], such that even patients with mild impairment will recruit these regions over and above controls. Patients with more marked impairment, however, seem to recruit them to a greater degree. Thus if one considers outcome as an explanatory variable there appears to be some consistency in the findings from different studies, at least those involving patients with subcortical infarcts.

The importance of distinguishing individual motor regions and perhaps subregions when interpreting brain mapping studies after stroke merits emphasis. Although M1 plays a pivotal role in the generation of fractionated movements, the cortical motor system is thought to consist of a number of independent parallel motor and sensorimotor loops that also includes PMd, SMA, CMA, and deep gray matter structures interconnected at the cortical level and with projections to spinal cord motor neurons [17]. These projections to spinal cord may play a role in the return of motor function after stroke, i.e., they may be recruited in response to damage to fast direct projections from M1 to spinal cord motor neurons. However, they are unlikely ever to completely substitute for those from M1 [18], explaining why patients reliant on secondary motor areas are left with some residual impairment.

Secondary motor areas can be further subdivided on the basis of function and cytoarchitecture. These subdivisions may be functionally important not least because some may influence motor behaviour through intact noncorticospinal pathways such as the reticulospinal tract, which receives bilateral inputs and projects to spinal interneurons that innervate distal motor neurons.

Cross-sectional studies of motor recovery cannot tell us about the evolution of the observed changes, which has obvious relevance to the process of reorganization. Longitudinal studies are considerably more difficult to implement, so few only are available. Those utilizing active motor tasks in patients with non-M1 infarcts tend to show early overactivations in many primary and secondary motor regions followed by a focusing towards a normal activation pattern [19-21], although one study demonstrated only increases in task-related activation in contralesional cerebellum with recovery [22]. In a study that used a composite measure of motor outcomes as an explanatory variable, early overactivations followed by reductions in a number of primary and secondary motor regions correlated negatively with recovery scores [23]. Such changes are reminiscent of those observed in the normal brain during motor skill learning [24].

Longitudinal studies employing passive rather than active movement are better suited to study patients with 
no residual movement in the early stages after stroke. In such studies there appears to be greater task-related activation at later compared to early stages post stroke in regions such as ipsilesional sensorimotor cortex and bilateral inferior parietal cortex $[25,26]$. The pattern of activation varied significantly as a function of outcome, with the magnitude of activation being lower than that of controls except for well-recovered patients [26]. This once again underlines the importance of acquiring behavioral measures as explanatory variables. The differences in results from active or passive movement paradigms are as yet unexplained, but illustrate the importance of task and patient selection in experimental design.

\section{Language Recovery Studies}

As in studies of motor recovery, the relative importance of the contralesional and ipsilesional hemispheres for recovery from aphasia has been intensively investigated. Evidence from cross-sectional [27] and longitudinal [28] studies suggests that return of left hemisphere language areas activation correlates with better behavioral outcome, whereas retention of right hemisphere activation correlates with poorer behavioral outcome. Nonetheless, some studies have shown correlation of good language recovery with emergence of homologous right hemisphere regions [29, 30]. Larger studies of language recovery will be needed to elucidate the role of contralesional activity early and late after stroke.

The details of network functional connectivity may be important to interpreting functional imaging studies after focal brain injury. In the above language studies, even when the left temporal lobe remained intact after stroke, activation may not be present during a language task if the patient is still aphasic, whereas that region's structural and functional integrity may be demonstrated by producing activation in that location in response to a non-language task, for example sound identification [31]. This task-dependent dissociation for activation in a given region demonstrates that brain regions may be involved in multiple networks related to different brain functions, and that it is functional connectivity rather than anatomical location per se that determines the resulting pattern of regional activity following neurological dysfunction and recovery after stroke. Furthermore, networks related to recovery of a given neurological function may be topographically distinct from networks related to performance of the function after recovery [32].

One approach to assessing the functional significance of changes in brain activation after stroke is to parametrically modulate behavioral demands and then examine changes in activation. Using a word-retrieval learning task, a functional contribution by right hemisphere activation was shown in a relatively homogeneous group of patients improved after aphasia by demonstrating a taskrelated modulation of activity in the right dorsal inferior frontal gyrus (IFG) that healthy control patients displayed in the left dorsal IFG [33].

In a recent longitudinal study [34], there was positive correlation between increased performance over time and flow activations in superior temporal regions bilaterally, stressing the importance of a bihemispheric network. Also, negative correlation between performance and flow in non-temporal regions - such as the right superior frontal cortex - were reported, i.e., recovery was associated with a gradual 'normalisation' of the pattern. Interestingly, similar negative correlation with increased performance was seen in normal subjects longitudinally, suggestive of (re)learning being part of the recovery process in the aphasics.

\section{Technical Challenges and Issues in Experimental Design and Analysis}

The results of functional imaging experiments are only as reliable as the care with which the experiment is constructed and executed. The choice of experimental task, patient monitoring, patient selection, and approaches to analysis require careful consideration if a study is to successfully address its stated hypothesis.

The choice of experimental task is dependent on the experimental question under consideration. For example, a study of the relationship between brain activation and outcome should involve stroke patients with different performance abilities. Similarly it is to be hoped that a longitudinal study or one involving a therapeutic intervention will involve patients with improving performance abilities. This approach requires two considerations. Firstly, the clinical status must be characterized in a detailed and relevant manner. Secondly, each patient must perform the same task during the acquisition of fMRI data so that a meaningful comparison can be made across subjects or scanning sessions.

A change in the features of an experimental task can have substantial effect upon the pattern of brain activation. Regarding motor tasks, for example, changes in task complexity [35], as well as force [36], frequency [37], or range [38] of movement all have an effect on the pattern of normal brain activation. Maintaining a consistent task is therefore of great importance, but in stroke recovery 
studies equality of task may be interpreted in a number of ways. In particular a task may be consistent across patients with different abilities in terms of absolute or relative parameters.

Considering a simple motor experiment, absolute task parameters can be fixed (by setting the same target force and rate for every scanning session) but performing a task may be experienced as more or less effortful depending on the level of recovery. Thus differences in results across subjects/sessions might be attributed to differences in 'effort' exerted. Alternatively, the level of task difficulty can be fixed across subjects/sessions (but patients will perform the task at different absolute forces and rates). Thus differences in results across subjects/sessions might be attributed to differences in the absolute task parameters. Results must always be interpreted with these confounds in mind.

These considerations can lead to difficulties in data interpretation. Increased effort is a potentially useful strategy for a patient with motor, language, or cognitive impairment, and patients may find a task less effortful as their performance improves. Is the focus of interest the underlying substrate of functional improvement or its consequence? Of course both may be of interest, but the choice of experimental design has an impact on which process is being studied. One approach is to build both approaches into the same study, e.g. [23], but this lengthens the experimental paradigm and time of scanning. Other approaches avoid the problem of performance confounds, e.g. passive limb movement, passive listening, but these are complementary approaches to active tasks, not substitutes for them.

One might also consider whether to use a task that is more likely to be relevant to each patient's disability, i.e. an ecologically valid task. However, patients with significant impairment are more likely to adopt new operational strategies towards such experimental tasks in an attempt to adapt to their impairment. Although of clinical interest, differences in strategy across a group represent a potential experimental confound if they are unexpected and not measured. One approach is therefore to use a simple task that minimizes difference in strategic approach to the task so that valid comparisons can then be made across subjects/sessions [39].

Once a paradigm has been selected it is important that task performance is monitored during the experiment. Normal intersubject variability can increase after stroke in light of changes in attention, mood, and other cognitive issues. Furthermore, new sources of variability can arise after stroke, such as a tendency towards mirror, or associated, movements. A number of solutions are available to address this concern. Some investigators record behavior during a pre-scan rehearsal [40]. Others incorporate the increasingly available instrumentation that is compatible with the MRI setting. This approach allows collected data to be incorporated into image analysis, thereby potentially improving statistical power by accounting for correlated variance in the measured scan signal.

Which patients should be scanned? Stroke patients are a heterogeneous group differing in age, site and size of infarct, patency of the arterial system, co-morbidities and concurrent medication. Patient selection will again depend on the experimental question. Results from highly selected patient subgroups may not generalize. Unselected groups however are susceptible to a number of uncontrolled variables, although it is possible to explore the effects of single factors (e.g. final outcome) or combinations of factors (e.g. final outcome, age, site of lesion) that best explain the variance in an imaging data set.

Collating data from different studies is hampered by the use of different experimental designs. Although two studies cannot be directly compared, data from both can contribute to the formation of a new testable hypothesis. Thus, in general, a single study should try to negate a single hypothesis generated from previous studies. For most questions this approach is entirely appropriate and standardization of experimental paradigms, patient selection and method of analysis across experiments is not required. In the case of an experimental question that requires a multi-centre approach, a technically feasible approach, standardization of such factors is required.

Several technical issues related to fMRI studies of stroke patients require further study. There is evidence that in patients with impaired cerebrovascular reserve or advanced narrowing of the cerebral arteries, the blood oxygen level-dependent (BOLD) fMRI signal may be reduced, or even become negative [41-43]. However, the chemical species most important to neuronal-vascular coupling of BOLD fMRI remains to be established, and so such data are of somewhat uncertain significance in the study of cerebrovascular disease. There is no evidence that the BOLD signal is erroneously detected in these patients, i.e. this is largely a problem of false negative results. It is not clear how the generation of the BOLD signal is affected by a number of parameters including time after stroke, large vessel disease and small vessel disease. A multimodal approach using different imaging techniques (BOLD, perfusion, hypercapnic challenge) and concurrent neurophysiological methods (EEG, MEG, TMS) may be useful when addressing the influence of multiple physiological variables. These issues will require further empirical study. 


\section{The Clinical Relevance of Brain Activation Patterns after Stroke: A Role for Transcranial Magnetic Stimulation?}

The behavioral significance of many of the changes in task-related brain activation following stroke remains unclear. Does an early shift of activity to the contralesional hemisphere, for example, mean compensatory networks are being recruited and the prognosis is good, or does it mean that the normal networks are dysfunctional and therefore the prognosis is poor? One simple explanation is that new regional activity seen with functional imaging represents recruitment and establishment of networks that have assumed a role in behavioral performance. In motor studies the significance of contralesional recruitment may be different for M1 compared to motor areas with more bilateral motor representation, such as PMd and SMA. Alternative explanations for changes after stroke are that new regional activity appears incidentally, as a consequence of the brain injury, for example as a result of infarction-induced disinhibition across the corpus callosum [44, 45], or that such activity reflects a nonspecific increase in effort or attention because the given task is more difficult for the post-stroke patient. Imaging cannot sort out this problem alone, and studies employing TMS to explore the functional utility of such activations have been helpful in this regard.

While the limitations of TMS must be kept in mind - a patch of cortex within a single brain area is subjected to a powerful stimulation, and a single output describes the effects of this stimulation upon numerous types of neurons - this approach is proving to be invaluable. A recent study of aphasic patients, for example, demonstrated disruption of language function during TMS stimulation of the right Broca-homologous region [46].

In motor recovery, disruption of ipsilesional PMd [47] and contralesional PMd [12] by TMS increases motor reaction times in chronic stroke patients but not controls, suggesting PMd in both hemispheres is important for recovery. By taking account of the effects of TMS in patients with different outcomes, a possible dissociation in their roles may be discerned. TMS to ipsilesional PMd was most disruptive in patients with least impairment [47] suggesting it may be capable of supporting good recovery. TMS to contralesional PMd however was most disruptive in patients with greater motor impairment [12] suggesting functionally relevant recruitment of contralesional PMd in those with greatest need.

Similar studies have been performed to examine the role of contralesional M1. Previously TMS studies have found that stimulation of contralesional M1 produces motor evoked responses in the ipsilateral affected hand most often in those patients with a poorer outcome [48, 49]. This is in keeping with the finding of increased recruitment of contralesional M1 in patients with poorer outcome $[12,13]$ but does not resolve the issue of whether it is functionally relevant. TMS-induced disruption of function in contralesional M1 does not affect movements of the affected limb [12, 50], suggesting that recruitment of the contralesional M1 does not simply correspond to a new activity to replace the function of the damaged area. Motor areas of the unaffected hemisphere do not take over the functions lost with stroke in any simple and direct way.

What then might be the significance of the task related overactivations that are consistently seen in unaffected motor cortex? A number of hypotheses have been suggested, including changes in interhemispheric inhibition, changes in the actual behavioral phenotype generated by patients, an expression of relative complexity, and substitution of an overactivating area for the function of an injured area.

Changes in inter-hemispheric interactions after stroke have been documented by TMS, made possible by the method's temporal resolution and its ability to study both excitation and inhibition. In terms of inhibition from the stroke hemisphere onto the non-stroke hemisphere, Shimizu et al. [51] described reduced inhibition within the contralesional M1 in patients with cortical stroke. In terms of inhibition from the contralesional M1 onto the ipsilesional M1, Murase et al. [45] found an abnormally high interhemispheric inhibitory drive over ipsilesional M1 during movement of the affected upper extremity. This abnormally high inhibitory influence upon stroke hemisphere motor areas could contribute to impairment. Future studies might assess the therapeutic potential arising from modifying either of these inhibitory drives using for example repetitive TMS to increase activity in the affected motor cortex or to decrease activity in the unaffected motor cortex. Other approaches might focus on directing bottom-up messages into the system, such as temporary deafferentation, forced use paradigms, passive movement, or somatosensory stimulation.

\section{The Development of Pharmacological and Behavioral Interventions}

Ultimately, this research aims to provide a basis for the development of rationale therapeutic strategies designed to restore function by minimizing impairment. Data de- 
rived from human brain mapping after stroke have the potential to provide useful information not available from other approaches such as behavioral exam or anatomical imaging. Functional imaging is unlikely to be useful purely as a marker of clinical improvement, something that is measurable with simple outcome scores. Functional imaging may be a useful marker of the potential for change in damaged brain. It is to be hoped that the potential of different therapeutic interventions can be assessed, both in groups and individuals. Serial studies over the course of a rehabilitation intervention have the potential to reveal patterns of brain reorganization that will guide decisions regarding optimal treatment intensity or duration as well as to track 'maladaptive' types of brain reorganization which inhibits functional recovery. Brain mapping data might provide insights into the biological mechanisms underlying treatment-related gains during rehabilitation and offer the possibility of more directly comparing effects in human stroke with those observed in animal models. To achieve such goals will require researchers to develop or adopt well-defined rehabilitation and adjunct approaches, identify outcome measures that are relevant to the interventions, create functional activation paradigms that reveal the cerebral networks engaged by the therapeutic strategies, and apply this overall strategy to patients who have a range of lesions, impairments, and disabilities.

Functional imaging methods have adequate sensitivity in many cases to demonstrate drug $[52,53]$ and rehabilitation effects [54-61] upon patients with stroke and in healthy subjects [62-66]. For example, a single dose of SSRI has been demonstrated to enhance motor network activation in a way that correlated with an improvement in motor performance in patients studied in the first month after stroke [52]. In aphasics, piracetam was associated with improvement in some language functions and with increased activity in left temporal and frontal regions [53]. A current challenge is to determine capability and optimal methods to identify recovery-related therapeutic targets and prognostic factors. Neuroimaging techniques have the potential to assess the effects of pharmacologic agents upon excitation, inhibition, and synaptic efficacy [67]. Some of the promise and confounds in deploying functional neuroimaging in the context of rehabilitation are anticipated by studies of activity-dependent plasticity and learning in normal subjects.

Physical and language interventions enjoy broad acceptance in clinical practice. However, an active area of investigation seeks to identify details of optimal modalities and approaches. What, when, and how are such interventions best applied? For example, should a patient have his paretic limb stimulated very early after stroke or would a better outcome result from delayed introduction of physical therapy? Which is the most efficacious approach across therapies? What duration, frequency, and scheduling will maximize outcome? It is hoped that functional imaging will help resolve these issues.

A number of pharmacologic interventions have been proposed for improving outcome after stroke. Based on experimental data such as that showing a depletion of monoamines after stroke, and on encouraging results in preclinical studies, mono-amine enhancers such as amphetamine and SSRIs may be promising approaches for improving motor and language deficits after stroke. The data from animal studies has unambiguously demonstrated that pharmacological manipulations are only effective in promoting recovery when paired with behavioral re-enforcement. That this is also the case in human studies requires empirical support. Again, functional imaging might afford better understanding into these complex questions.

Brain mapping studies using TMS provide insights into the effects of specific drugs on cortical plasticity. Such studies have demonstrated, for example, that alpha and beta blockers, anticholinergics, NMDA antagonists and gabaergic drugs can exert deleterious effects on human use-dependent plasticity [68-71] while others such as D-amphetamine or levodopa enhance use-dependent plasticity $[69,72]$ or even elicit plasticity in individuals unresponsive to motor training alone [73]. All these studies assessed effects of single dose of drugs and chronic treatments, as those which will be given in patients, must now be tested. In this regard, chronic treatment in healthy subjects may have effects on brain function that are opposite to those of a single dose possibly due to processes such as down-regulation of stimulated receptors [67, 74]. Such assessments, based on neurophysiology and chemistry, might permit treatment decisions that are more precise than those made on clinical history or exam.

In some respects, the results of human brain mapping are only as good as the clinical/behavioral measures to which they are compared. The psychometric requirements of good clinical scales and behavioral outcome measures are many, for example, they must have the sensitivity to demonstrate therapeutic improvement. Tasks unrelated to the deficit of interest might also be tested, such as attention, to assess the extent to which a drug might achieve effect via modified cognitive function.

Further studies are needed to define the potential for human brain mapping to serve as a surrogate marker of restorative events, or as an alternative to clinical endpoints in clinical rehabilitation studies after stroke. From 
the description of currently available studies given in previous sections there is clearly some way to go before achieving this goal. Experiments need to become more hypothesis-driven and a clearer understanding of the issues surrounding experimental design is required.

\section{Conclusions}

There is burgeoning evidence that the human brain responds to ischemic injury with mechanisms to promote recovery of function both earlier and later than had been previously suspected. Imaging techniques such as fMRI and PET as well as related neurophysiological techniques like TMS, EEG and MEG have demonstrated that the human brain has not only the capacity to activate alternative regions during recovery, but that the system is a dynamic one, subject to behavioral and pharmacological interventions that could potentiate recovery. Although there are many questions still to answer, clinicians and scientists now have a responsibility to come together to ask appropriate questions in a rigorous manner. We can be reasonably optimistic that future studies will translate into true benefits for patients with stroke.

\section{References}

1 Calautti C, Baron JC: Functional neuroimaging studies of motor recovery after stroke in adults: a review. Stroke 2003;34:1553-1566.

$\checkmark 2$ Chen R, Cohen LG, Hallett M: Nervous system reorganization following injury. Neuroscience 2002;111:761-773.

3 Cramer SC, Bastings EP: Mapping clinically relevant plasticity after stroke. Neuropharmacology 2000;39:842-851.

4 Rijntjes M, Weiller C: Recovery of motor and language abilities after stroke: the contribution of functional imaging. Prog Neurobiol 2002;66: 109-122.

$>5$ Herholz K, Heiss WD: Functional imaging correlates of recovery after stroke in humans. $J$ Cereb Blood Flow Metab 2000;20:1619-1631.

6 Chollet F, DiPiero V, Wise RJ, Brooks DJ, Dolan RJ, Frackowiak RS: The functional anatomy of motor recovery after stroke in humans: a study with positron emission tomography. Ann Neurol 1991;29:63-71.

7 Weiller C, Chollet F, Friston KJ, Wise RJ, Frackowiak RS: Functional reorganization of the brain in recovery from striatocapsular infarction in man. Ann Neurol 1992;31:463-472.

8 Weiller C, Ramsay SC, Wise RJ, Friston KJ, Frackowiak RS: Individual patterns of functional reorganization in the human cerebral cortex after capsular infarction. Ann Neuro 1993;33:181-189.

9 Cramer SC, Nelles G, Benson RR, Kaplan JD, Parker RA, Kwong KK, Kennedy DN, Finklestein SP, Rosen BR: A functional MRI study of subjects recovered from hemiparetic stroke. Stroke 1997;28:2518-2527.

-10 Seitz RJ, Hoflich P, Binkofski F, Tellmann L, Herzog H, Freund HJ: Role of the premotor cortex in recovery from middle cerebral artery infarction. Arch Neurol 1998;55:1081-1088.

$\checkmark 11$ Calautti C, Leroy F, Guincestre JY, Baron JC Dynamics of motor network overactivation after striatocapsular stroke: a longitudinal PET study using a fixed-performance paradigm. Stroke 2001:32:2534-2542.

12 Johansen-Berg H, Rushworth MF, Bogdanovic MD, Kischka U, Wimalaratna S, Matthews PM: The role of ipsilateral premotor cortex in hand movement after stroke. Proc Natl Acad Sci USA 2002;99:14518-14523.
13 Ward NS, Brown MM, Thompson AJ, Frackowiak RS: Neural correlates of outcome after stroke: a cross-sectional fMRI study. Brain 2003;126:1430-1448.

14 Calautti C, Naccarato M, Jones P, Day D, Fletcher P, Carpenter T, Bullmore ET, Warburton E, Baron J: Motor performance in the stable phase of recovery after subcortical stroke is related to laterality of motor network activation. Stroke 2004;35:285.

15 Calautti C, Leroy F, Guincestre JY, Baron JC: Displacement of primary sensorimotor cortex activation after subcortical stroke: a longitudinal PET study with clinical correlation. Neuroimage 2003;19:1650-1654.

16 Pineiro R, Pendlebury S, Johansen-Berg H, Matthews PM: Functional MRI detects posterior shifts in primary sensorimotor cortex activation after stroke: evidence of local adaptive reorganization? Stroke 2001;32:1134-1139.

17 Strick PL: Anatomical organization of multiple motor areas in the frontal lobe: implications for recovery of function. Adv Neurol 1988;47: 293-312.

18 Maier MA, Armand J, Kirkwood PA, Yang HW, Davis JN, Lemon RN: Differences in the corticospinal projection from primary motor cortex and supplementary motor area to macaque upper limb motoneurons: an anatomical and electrophysiological study. Cereb Cortex 2002; 12:281-296.

19 Marshall RS, Perera GM, Lazar RM, Krakauer JW, Constantine RC, DeLaPaz RL: Evolution of cortical activation during recovery from corticospinal tract infarction. Stroke 2000;31: 656-661.

20 Calautti C, Leroy F, Guincestre JY, Marie RM, Baron JC: Sequential activation brain mapping after subcortical stroke: changes in hemispheric balance and recovery. Neuroreport 2001;12: 3883-3886.

21 Feydy A, Carlier R, Roby-Brami A, Bussel B, Cazalis F, Pierot L, Burnod Y, Maier MA: Longitudinal study of motor recovery after stroke: recruitment and focusing of brain activation. Stroke 2002;33:1610-1617.

22 Small SL, Hlustik P, Noll DC, Genovese C, Solodkin A: Cerebellar hemispheric activation ipsilateral to the paretic hand correlates with functional recovery after stroke. Brain 2002; 125:1544-1557.

23 Ward NS, Brown MM, Thompson AJ, Frackowiak RS: Neural correlates of motor recovery after stroke: a longitudinal fMRI study. Brain 2003;126:2476-2496.

24 Hikosaka O, Nakamura K, Sakai K, Nakahara $\mathrm{H}$ : Central mechanisms of motor skill learning. Curr Opin Neurobiol 2002;12:217-222.

25 Nelles G, Spiekramann G, Jueptner M, Leonhardt G, Muller S, Gerhard H, Diener HC: Evolution of functional reorganization in hemiplegic stroke: A serial positron emission tomographic activation study. Ann Neurol 1999;46:901-909.

26 Loubinoux I, Carel C, Pariente J, Dechaumont S, Albucher JF, Marque P, Manelfe C, Chollet $\mathrm{F}$ : Correlation between cerebral reorganization and motor recovery after subcortical infarcts. Neuroimage 2003;20:2166-2180.

27 Cao Y, Vikingstad EM, George KP, Johnson $\mathrm{AF}$, Welch KM: Cortical language activation in stroke patients recovering from aphasia with functional MRI. Stroke 1999;30:2331-2340.

28 Heiss WD, Kessler J, Thiel A, Ghaemi M, Karbe H: Differential capacity of left and right hemispheric areas for compensation of poststroke aphasia. Ann Neurol 1999;45:430-438.

29 Musso M, Weiller C, Kiebel S, Muller SP, Bulau P, Rijntjes M: Training-induced brain plasticity in aphasia. Brain 1999;122:1781-1790.

30 Thulborn KR, Carpenter PA, Just MA: Plasticity of language-related brain function during recovery from stroke. Stroke 1999;30:749-754.

31 Price CJ, Warburton EA, Moore CJ, Frackowiak RS, Friston KJ: Dynamic diaschisis: anatomically remote and context-sensitive human brain lesions. J Cogn Neurosci 2001;13:419_ 429.

32 Seitz RJ, Azari NP, Knorr U, Binkofski F, Herzog H, Freund HJ: The role of diaschisis in stroke recovery. Stroke 1999;30:1844-1850.

33 Blasi V, Young AC, Tansy AP, Petersen SE, Snyder AZ, Corbetta M: Word retrieval learning modulates right frontal cortex in patients with left frontal damage. Neuron 2002;36:159_ 170.

34 Cardebat D, Demonet JF, De B, X, Marie N, Marie RM, Lambert J, Baron JC, Puel M: 
Behavioral and neurofunctional changes over time in healthy and aphasic subjects: a PET Language Activation Study. Stroke 2003;34: 2900-2906.

-35 Catalan MJ, Honda M, Weeks RA, Cohen LG, Hallett M: The functional neuroanatomy of simple and complex sequential finger movements: a PET study. Brain 1998;121:253-264.

-36 Dettmers C, Fink GR, Lemon RN, Stephan KM, Passingham RE, Silbersweig D, Holmes A, Ridding MC, Brooks DJ, Frackowiak RS: Relation between cerebral activity and force in the motor areas of the human brain. J Neurophysiol 1995;74:802-815.

- 37 Rao SM, Bandettini PA, Binder JR, Bobholz JA, Hammeke TA, Stein EA, Hyde JS: Relationship between finger movement rate and functional magnetic resonance signal change in human primary motor cortex. J Cereb Blood Flow Metab 1996;16:1250-1254.

>38 Waldvogel D, van Gelderen P, Ishii K, Hallett M: The effect of movement amplitude on activation in functional magnetic resonance imaging studies. J Cereb Blood Flow Metab 1999; 19:1209-1212.

-39 Poldrack RA: Imaging brain plasticity: conceptual and methodological issues - a theoretical review. NeuroImage 2000;12:1-13.

-40 Nelles G, Cramer SC, Schaechter JD, Kaplan JD, Finklestein SP: Quantitative assessment of mirror movements after stroke. Stroke 1998; 29:1182-1187.

-41 Carusone LM, Srinivasan J, Gitelman DR, Mesulam MM, Parrish TB: Hemodynamic response changes in cerebrovascular disease: implications for functional MR imaging. AJNR Am J Neuroradiol 2002;23:1222-1228.

$\checkmark 42$ Hamzei F, Knab R, Weiller C, Rother J: The influence of extra- and intracranial artery disease on the BOLD signal in FMRI. NeuroImage 2003;20:1393-1399.

$\checkmark 43$ Rossini PM, Altamura C, Ferretti A, Vernieri F, Zappasodi F, Caulo M, Pizzella V, Del Gratta C, Romani GL, Tecchio F: Does cerebrovascular disease affect the coupling between neuronal activity and local haemodynamics? Brain 2004; 127:99-110.

-44 Meyer BU, Roricht S, von Einsiedel G, Kruggel F, Weindl A: Inhibitory and excitatory interhemispheric transfers between motor cortical areas in normal humans and patients with abnormalities of the corpus callosum. Brain 1995 118:429-440.

45 Murase N, Duque J, Mazzocchio R, Cohen LG: Influence of interhemispheric interactions on motor function in chronic stroke. Ann Neurol 2004;55:400-409

46 Heiss WD, Thiel A, Winhuisen L, Habedank B, Kessler J, Haupt WF: Identification of areas with relevant functional activation by rTMS Ann Neurol 2003;54(suppl 7):S78.

$\checkmark 47$ Fridman EA, Hanakawa T, Chung M, Hummel F, Leiguarda RC, Cohen LG: Reorganization of the human ipsilesional premotor cortex after stroke. Brain 2004; 127:747-758.

48 Netz J, Lammers T, Homberg V: Reorganization of motor output in the non-affected hemisphere after stroke. Brain 1997;120:15791586.

49 Turton A, Wroe S, Trepte N, Fraser C, Lemon $\mathrm{RN}$ : Contralateral and ipsilateral EMG re- sponses to transcranial magnetic stimulation during recovery of arm and hand function after stroke. Electroencephalogr Clin Neurophysiol 1996;101:316-328.

50 Werhahn KJ, Conforto AB, Kadom N, Hallett M, Cohen LG: Contribution of the ipsilateral motor cortex to recovery after chronic stroke. Ann Neurol 2003;54:464-472.

51 Shimizu T, Hosaki A, Hino T, Sato M, Komori T, Hirai S, Rossini PM: Motor cortical disinhibition in the unaffected hemisphere after unilateral cortical stroke. Brain 2002;125:18961907.

52 Pariente J, Loubinoux I, Carel C, Albucher JF, Leger A, Manelfe C, Rascol O, Chollet F: Fluoxetine modulates motor performance and cerebral activation of patients recovering from stroke. Ann Neurol 2001;50:718-729.

53 Kessler J, Thiel A, Karbe H, Heiss WD: Piracetam improves activated blood flow and facilitates rehabilitation of poststroke aphasic patients. Stroke 2000;31:2112-2116.

54 Bastings EP, Greenberg JP, Good DC: Hand motor recovery after stroke: a transcranial magnetic stimulation mapping study of motor output areas and their relation to functional status. Neurorehabil Neural Repair 2002;16: 275-282.

55 Carey JR, Kimberley TJ, Lewis SM, Auerbach EJ, Dorsey L, Rundquist P, Ugurbil K: Analysis of fMRI and finger tracking training in subjects with chronic stroke. Brain 2002;125:773788.

56 Jang SH, Kim YH, Cho SH, Lee JH, Park JW, Kwon YH: Cortical reorganization induced by task-oriented training in chronic hemiplegic stroke patients. Neuroreport 2003;14:137-141.

57 Johansen-Berg H, Dawes H, Guy C, Smith SM, Wade DT, Matthews PM: Correlation between motor improvements and altered fMRI activity after rehabilitative therapy. Brain 2002;125: 2731-2742.

58 Liepert J, Bauder H, Wolfgang HR, Miltner WH, Taub E, Weiller C: Treatment-induced cortical reorganization after stroke in humans. Stroke 2000;31:1210-1216.

$>59$ Nelles G, Jentzen W, Jueptner M, Muller S, Diener HC: Arm training induced brain plasticity in stroke studied with serial positron emission tomography. NeuroImage 2001;13: 1146-1154.

60 Schaechter JD, Kraft E, Hilliard TS, Dijkhuizen RM, Benner T, Finklestein SP, Rosen BR, Cramer SC: Motor recovery and cortical reorganization after constraint-induced movement therapy in stroke patients: a preliminary study. Neurorehabil Neural Repair 2002;16:326338.

61 Wittenberg GF, Chen R, Ishii K, Bushara KO, Eckloff S, Croarkin E, Taub E, Gerber LH, Hallett M, Cohen LG: Constraint-induced therapy in stroke: magnetic-stimulation motor maps and cerebral activation. Neurorehabil Neural Repair 2003; 17:48-57.

62 Furey ML, Pietrini P, Haxby JV, Alexander GE, Lee HC, VanMeter J, Grady CL, Shetty U, Rapoport SI, Schapiro MB, Freo U: Cholinergic stimulation alters performance and taskspecific regional cerebral blood flow during working memory. Proc Natl Acad Sci USA 1997:94:6512-6516.
63 Grasby PM, Friston KJ, Bench CJ, Frith CD, Paulesu E, Cowen PJ, Liddle PF, Frackowiak RS, Dolan R: The effect of apomorphine and buspirone on regional cerebral blood flow during the performance of a cognitive task - measuring neuromodulatory effects of psychotropic drugs in man. Eur J Neurosci 1992;4:12031212.

64 Lotze M, Braun C, Birbaumer N, Anders S, Cohen LG: Motor learning elicited by voluntary drive. Brain 2003;126:866-872.

65 Loubinoux I, Boulanouar K, Ranjeva JP, Carel C, Berry I, Rascol O, Celsis P, Chollet F: Cerebral functional magnetic resonance imaging activation modulated by a single dose of the monoamine neurotransmission enhancers fluoxetine and fenozolone during hand sensorimotor tasks. J Cereb Blood Flow Metab 1999; 19:1365-1375.

66 Loubinoux I, Pariente J, Boulanouar K, Carel C, Manelfe C, Rascol O, Celsis P, Chollet F: A single dose of the serotonin neurotransmission agonist paroxetine enhances motor output: double-blind, placebo-controlled, fMRI study in healthy subjects. NeuroImage 2002;15:2636.

67 Gerdelat A, Tombari D, Loubinoux I, Chollet F, Simonetta-Moreau M: Does chronic serotonin re-uptake inhibitor paroxetine treatment modulate human motor cortex excitability in healthy subjects? A TMS study. 9th International Conference on Functional Mapping of the Human Brain, June 19-22, 2003, New York, NY. Available on CD-Rom in NeuroImage 2003; 19:abstr 1072

68 Butefisch CM, Davis BC, Wise SP, Sawaki L, Kopylev L, Classen J, Cohen LG: Mechanisms of use-dependent plasticity in the human motor cortex. Proc Natl Acad Sci USA 2000;97: 3661-3665.

69 Butefisch CM, Davis BC, Sawaki L, Waldvogel D, Classen J, Kopylev L, Cohen LG: Modulation of use-dependent plasticity by d-amphetamine. Ann Neurol 2002;51:59-68.

70 Donchin O, Sawaki L, Madupu G, Cohen LG Shadmehr R: Mechanisms influencing acquisition and recall of motor memories. $\mathrm{J}$ Neurophysiol 2002;88:2114-2123.

71 Sawaki L, Werhahn KJ, Barco R, Kopylev L, Cohen LG: Effect of an alpha(1)-adrenergic blocker on plasticity elicited by motor training. Exp Brain Res 2003;148:504-508.

72 Floel A, Celnik P, Sawali L: Enhancement of use-dependent plasticity by levodopa. 10th International conference for Functional Mapping of the Human Brain, June 13-17, 2004, Budapest, Hungary. Available on CD-Rom in NeuroImage 2004; abstr TU17.

73 Sawaki L, Cohen LG, Classen J, Davis BC, Butefisch CM: Enhancement of use-dependent plasticity by D-amphetamine. Neurology 2002 59:1262-1264.

74 Loubinoux I, Tombari D, Pariente J, Gerdelat A, Pastor J, Cassol E, Rascol O, Chollet F: Modulation of behavior and cerebral fmri activation after serotonine enhancers. Chronic versus acute effects. 10th International conference for Functional Mapping of the Human Brain, June 13-17, 2004, Budapest, Hungary. Available on CD-Rom in NeuroImage 2004; abstr WE39. 